\title{
ARTICLE \\ Slackening of Food Supply Chain during COVID-19 and Affecting Livelihood - A Global Concern
}

\author{
Ambika Prasad Mishra ${ }^{1}$ Jyoti Prakash Sahoo ${ }^{2 *}$ \\ 1. Department of Soil Science, Faculty of Agriculture, Sri Sri University, Cuttack, Odisha, India \\ 2. Department of Agricultural Biotechnology, Odisha University of Agriculture and Technology, Bhubaneswar, India
}

\section{ARTICLE INFO}

Article history

Received: 8 June 2021

Accepted: 21 June 2021

Published Online: 6 July 2021

\section{Keywords:}

COVID-19

Lockdown

Pandemic

Food supply chain

Agriculture

\begin{abstract}
The outbreak of COVID-19 has brought about another age on world as the human civilization is restricted in many aspects of everyday lives. There is no exception in the sector of food production and the supply chain of food. Due to constraints on demand, shutting of food production facilities, financial limitations, enterprise operations and delivery of different food items have been interrupted in the food supply chain. Every nation must comprehend the importance of the situation according to the spreading scenario of the ongoing pandemic. The probability of transmission via the food sector is regarded inconsequential, and the public authorities do not believe it necessary to follow COVID into workplaces. The unfavourable effects on the climate, the food framework and the people of the foodstuffs network are evident. An installation for the food supply chain should focus on amenities such as maintaining the safety and health of employees and changing working circumstances. This paper aims at discussing the effects of COVID-19 on the socio-economic status of human being including the negative impacts on the agriculture and food supply chain.
\end{abstract}

\section{Introduction}

A pandemic is not a novel phenomenon in human history, since mankind has experienced a variety of pandemics throughout history. Considering one of the major areas of the economy, the food supply chain, COVID-19 has an influence on the complete process from the field to the consumer. Due to the recent issues of COVID-19 lockdown, the food production, processing, distribution and demand have become a source of substantial worry in the food supply chain. COVID-19 has led to limits on the migra- tion of employees, changes in consumer demand, closure of food production facilities, limited rules on the trade of food products and financial constraints on the food supply chain. Governments should therefore promote workers' and agri-food migration. Furthermore, financial help should be given to smallholder farmers or needy persons. On 11 March 2020 speech, the WHO called on nations to plan preventive and reactive action in line with the Global Strategic Preparedness and Response Plan, which identified the fast spreading COVID-19 as pandemic ${ }^{[1,2]}$.

WHO noted that this outbreak is not only a crisis of

*Corresponding Author:

Jyoti Prakash Sahoo,

Department of Agricultural Biotechnology, Odisha University of Agriculture and Technology, Bhubaneswar, India;

Email: jyotiprakashsahoo2010@gmail.com 
public health, but also a problem affecting all sectors. Each industry and each individual should thus participate in this fight against COVID-19 ${ }^{[3]}$. On March 11, 2020, WHO proclaimed the emergence of COVID-19 to be a worldwide pandemic ${ }^{[4]}$. Many people are affected by the virus, if the world scenario is considered (Figure 1). COVID-19 is anticipated to have a greater impact on the global economy.

Agriculture is one of the most significant industries in global economy. Food safety and human development are vital for agriculture. More than $60 \%$ of the world's population is estimated by FAO to rely on agriculture for survival ${ }^{[5]}$. In the current worldwide COVID-19 pandemic, the impact of COVID-19 on food and agriculture is crucial and enormous. COVID-19 influenced all the procedures connecting agricultural production to the end consumer. In addition, the food system and the value chain appear to be striking. The negative effects of the pandemic on food supplies and demand might challenge food safety. The recession that has already started in Europe and the Unit- ed States is projected to depress economic activity across developed countries by $6 \%$ on average in 2020 , despite an expected rebound later in the year as social distancing measures are lifted and stimulus measures take effect. This recession will spill over to the rest of the world through lower demand for trade and lower commodity prices. Developing economies will be hurt by the economic fallout caused by their own social distancing measures and by increased morbidity affecting the labor supply for farming and other business activity. For developing countries as a group, the economic fallout would lead to a decline of their aggregate GDP of 3.6\% (Figure 2), but economies in Africa south of the Sahara, Southeast Asia, and Latin America would be hit much harder due to their relatively high dependence on trade and primary commodity exports ${ }^{[6]}$. The recession is expected to be less severe in China and the rest of East Asia, where we expect the economic recovery to start sooner with the earlier lifting of containment measures ${ }^{[6]}$. This review aims at examining the consequences of COVID-19 on the socio-economic condition

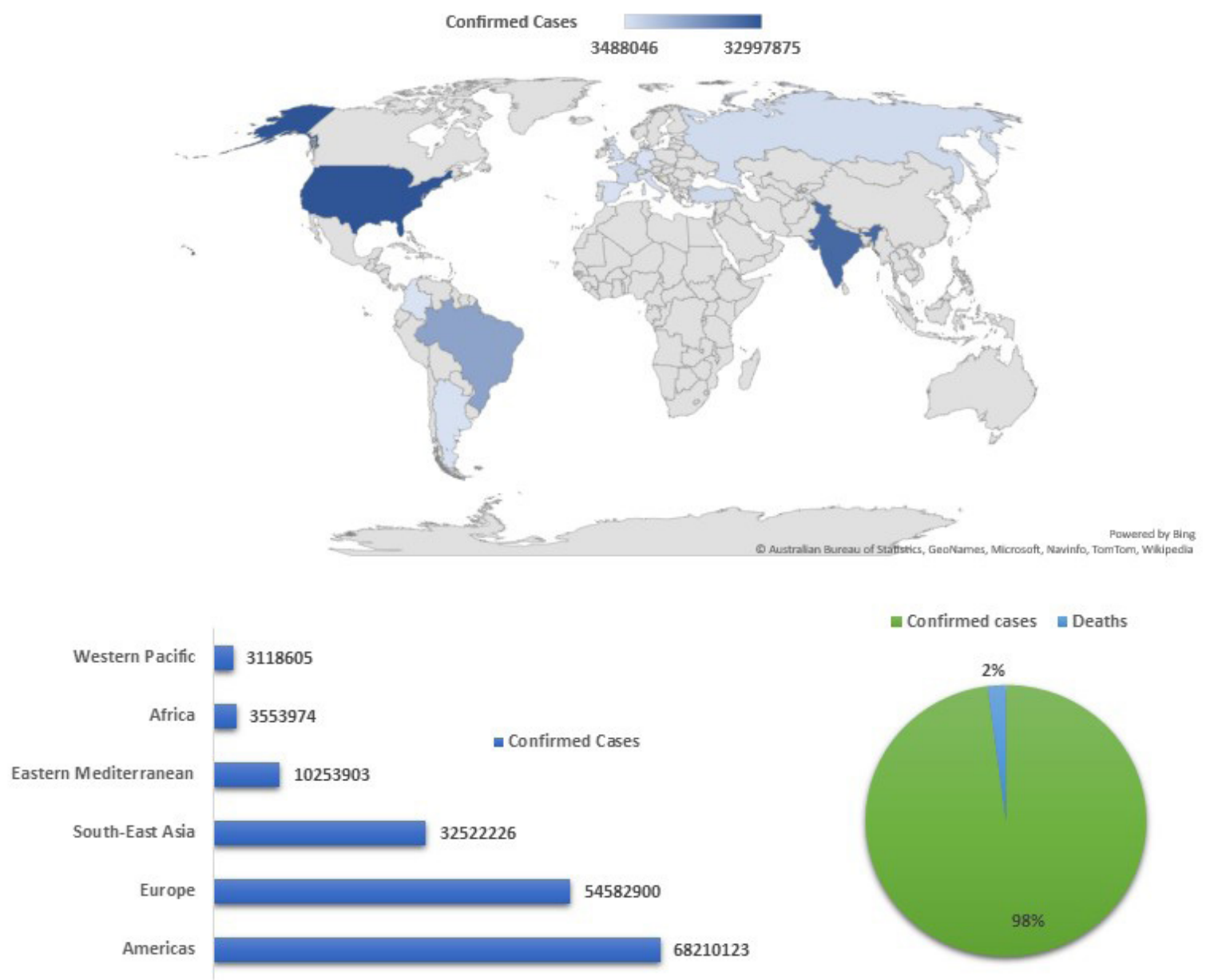

Figure 1. Globally scenario of COVID-19 till $5^{\text {th }}$ June, 2021 


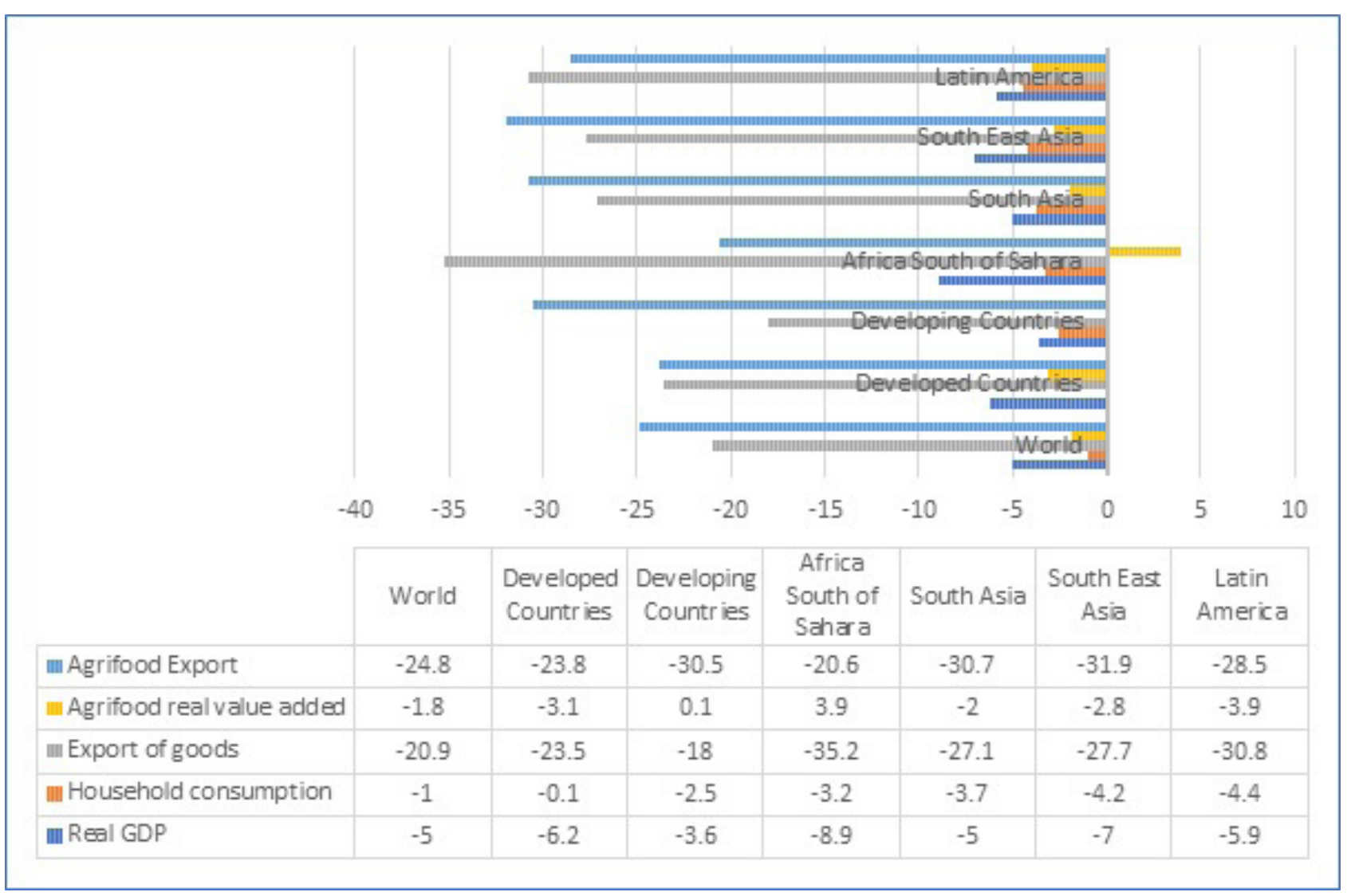

Figure 2. COVID-19 global economic recession in 2020 (\% change from base year values) ${ }^{[6]}$

of human being including the detrimental effects on the agricultural and food supply chain.

\section{Impact of COVID-19 on Food Production and Distribution}

Most governments across globe have taken steps to restrict the infection rate, such as home quarantine, travel bans and the shutdown protocols. This limitation of mobility has a significant influence on food distribution throughout all the stages of the food supply chain (Figure 3 ). The world market in goods is expected to fall from COVID-19 by 13 percent to 22 percent ${ }^{[7]}$. Different agricultural sectors have suffered severe pandemics, including crops, animals and fisheries. Owing to limited availability of animal feed and a scarcity of work in India, COVID-19 has a greater impact on livestock production. Fish is an essential protein and energy source and accounting for more than 3 million individuals for more than 20 percent of animal protein. In the same way, the marketing of milk has been hindered by prolonged lockdown, coupled with closing hotels and restaurants.

During the lockdown, milk cooperatives are thus unable to supply milk to dairy producers. Farmers lack fundamental inputs such as seeds, fertilisers and insecti- cides because of global trade disturbances. China is one of the world's largest manufacturers of fertilisers and exports. The Chinese lockdown has a major impact on global commerce in fertilizers ${ }^{[8]}$. Spring crops such as maize, sunflower, spring wheat, barley, canola, open field vegetables have been harmed by this pandemic. In kharif season, scientists claim that, India requires 250 lakh quintals of seed for cultivation practices ${ }^{[9]}$. So, if the pandemic continues, sowing of rabi and kharif seasonal crops might be adversely affected. In the farming business, health care and labour shortages for workers have been of great concern with the high incidence of transmission of COVID-19. Low and intermediate workers in nations lack adequate health and social protection services and, owing to a little amount of savings or no savings, many informal agriculturists are obligated to work during the COVID-19 epidemic, despite the self-isolation protocol as there is a substantial risk of the COVID-19 for these workers ${ }^{[10]}$. Most agricultural producers have a scarcity of labour. Employment losses are growing rapidly worldwide. Many Government and NGOs perform their part in keeping the food supply chain constant to overcome these eventualities. Currently the FAO is focusing on maintaining the food value chain and maintaining the food supply. This is 


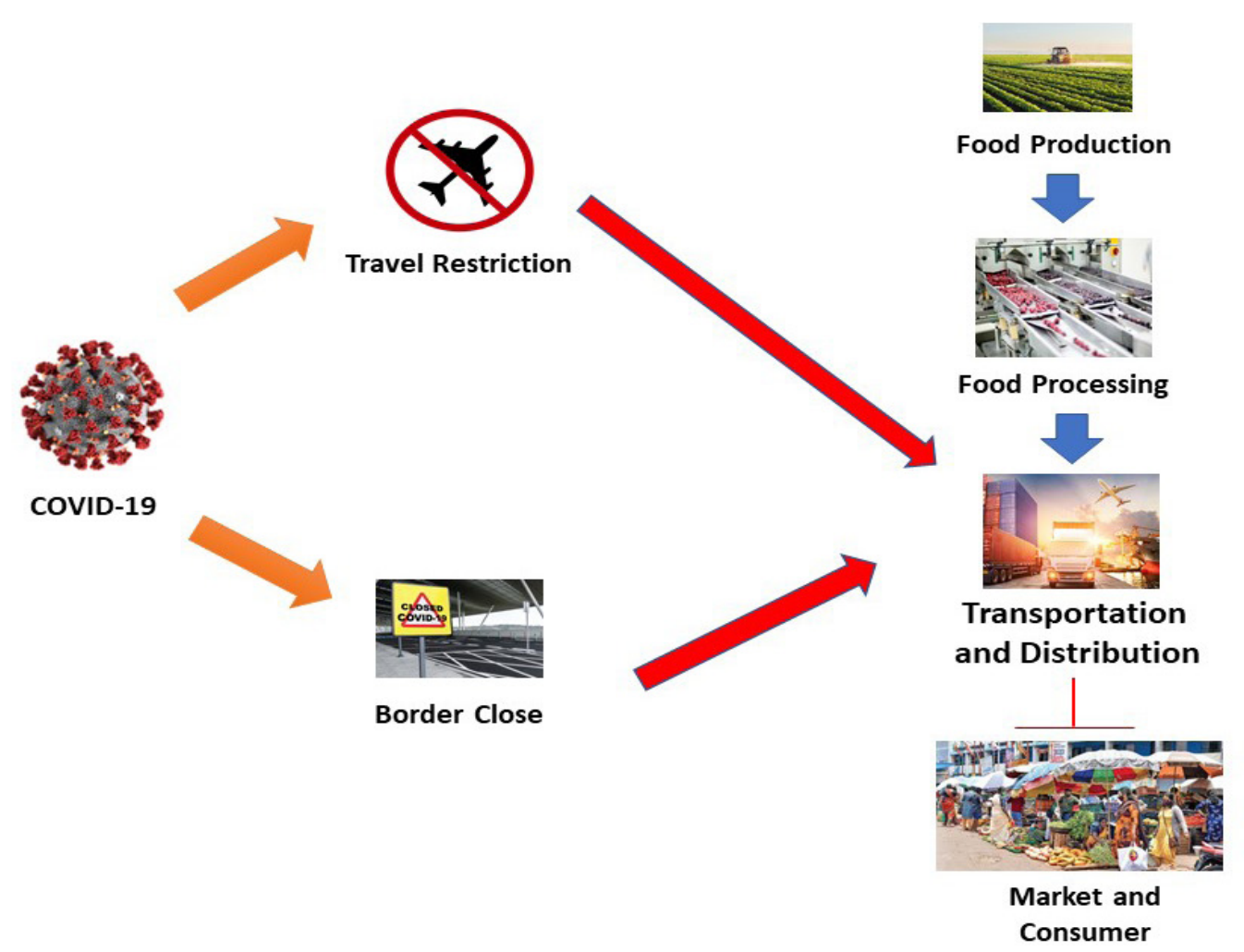

Figure 3. COVID-19 affecting food supply chain with major impact on food transport and distribution

the major purpose of the FAO. The major problems in the foodstuff supply chain are the procurement and continuation of food chains from manufacturers to end consumers ${ }^{[11]}$. The challenges threaten the capacity of farmers to continue their business as usual, and can adversely affect the quality of food, freshness and food safety, and prevent market access and cost ${ }^{[12]}$.

\section{Impact of COVID-19 on Food Demand and Food Security}

Food safety only refers to the continuous availability and accessibility of enough healthy food. Food insecurity might emerge as a result of a reduction in international commerce, food supply chain disruption and food production. The FAO has stated that it might be difficult for small-scale farmers and fishermen to buy their product that would in turn lower their revenue and capability. In the lowest and vulnerable sectors of population, the food insecurity increased by the COVID-19 would be heavily affected ${ }^{[13]}$. Currently, 820 million people suffer from chronic starvation, while 113 million suffer from acute insecurity ${ }^{[14]}$. Thus, food availability disturbances caused by the pandemic severely affect these people. Approximately 10 million youngsters rely on food to meet their dietary needs. However, while schools are closed and school meal programmes suspended, these youngsters will no longer have regular school meals, which can diminish their illness capacity ${ }^{[15]}$. The use of animal protein has reduced considerably in the current circumstances as a result of a mistaken view of the animal as a viral reservoir. The supply chain affects manufacturers, distributors and consumers as well as labour-intensive food processing factories. Production in numerous facilities was decreased, suspended and temporarily stopped because of employees who were tested COVID positive and were unwilling to go to work, believing that they were sick at work, mostly in enterprises producing meat products during the epidemic.

For these reasons, pork production capacity in late April was projected to drop by around 25 per cent ${ }^{[16,17]}$. Closing of food plants has generated a food supply chain ripple effect. Greater demand on the part of consumers resulted in bare shelves and a reduction in the availability of meat items prompted increased prices. Some marketplaces have restricted the quantity of products a buyer wishes to buy, such as beef and pork. Another element that caused food chains disruption during the COVID-19 pandemic is centralised production of food. This paradigm has helped to improve productivity and cut expenses for the food processors. However, there are certain negatives to centralization, such as tight and long supply chains. Furthermore, the use of the small number of really large production facilities to satisfy demand may generate challenges ${ }^{[18]}$. COVID-19 is spreading through the developing 


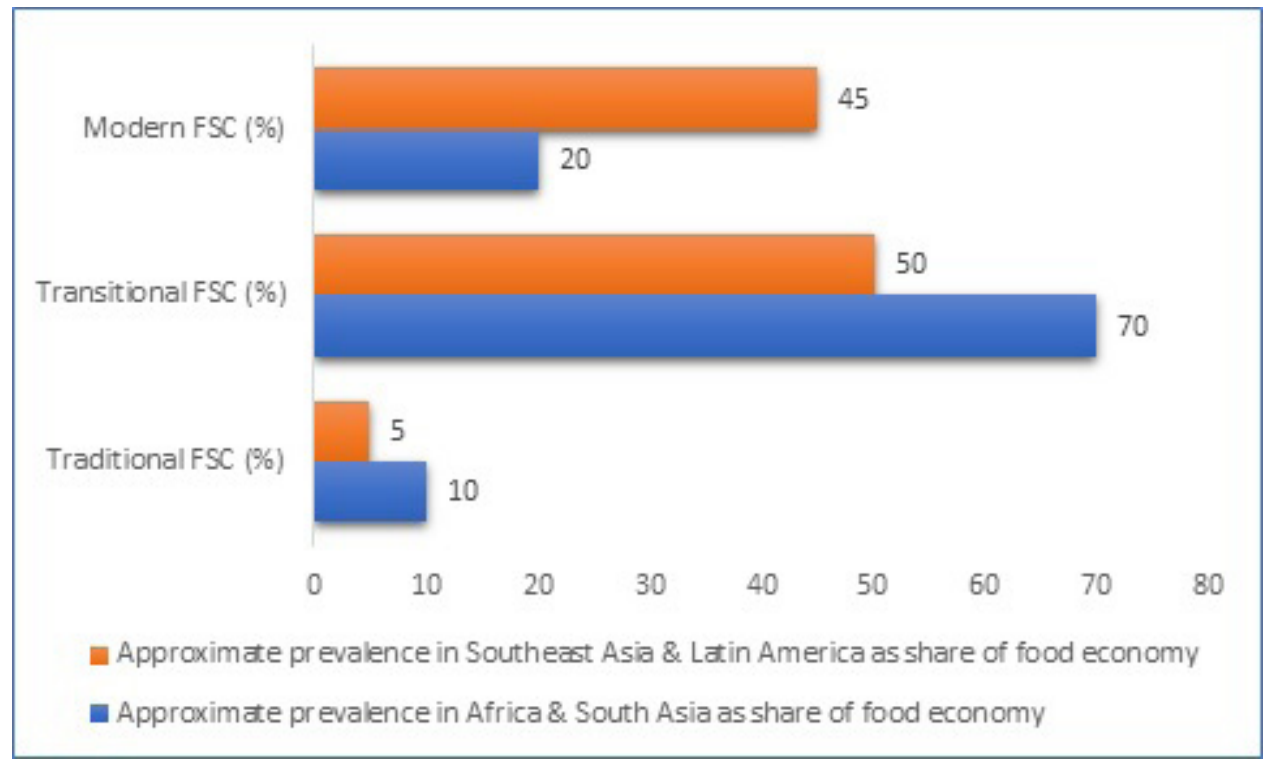

Figure 4. The three stages of food supply chains and their prevalence in the food economy

world. Many low- and middle-income countries are now reporting growing numbers of cases and imposing rigorous lockdown regulations in response, which impact all aspects of the economy. Most urban and rural consumers now depend on markets, in contrast to 30 to 40 years ago when a large share of rural populations lived "off the grid" in subsistence agriculture. Consumers purchase $80 \%$ of all food consumed in Africa and Asia, and thus FSCs (Food supply Chain) provide $80 \%$ of all food consumed Modern FSCs (dominated by large processing firms and supermarkets, capital-intensive, with relatively low labour-intensity of operations) constitute roughly $30 \%-50 \%$ of the food systems in China, Latin America, and Southeast Asia, and $20 \%$ of the food systems in Africa and South Asia. Transitional FSCs (stretching from rural to urban areas, fragmented and dominated by thousands of labour-intensive SMEs - small and medium-sized enterprises) dominate food systems, constituting $50 \%-80 \%$ of the food economies of developing Asia and Africa (Figure 4). SMEs in transitional FSCs in developing countries tend to be found in clusters such as dense sets of food processing SMEs, scores of meal vendors at truck stops, and dense masses of wholesalers and retailers in public wholesale markets and wet markets ${ }^{[18]}$. Each of these clusters could have numerous SMEs.

\section{Effects of COVID-19 on Consumer Behaviour}

Outreach COVID-19 scenario is disturbing the everyday routine. Furthermore, confinement has caused individuals' tension and driven them towards succulent food for a great sensation. Due to their capacity to promote serotonin synthesis, carbohydrate-rich meals can be em- ployed as self-medical components. This improper eating pattern however can lead to obesity associated with chronic inflammation and significant COVID-19 problems ${ }^{[19]}$. The shutdown of restaurants and restricted food service venues altered food or buying patterns and led to an unexpected shift of demand from food to retail. Reports have shown that the ratio of food purchases and food services to supermarkets was $50 \%$ before the pandemic, while for supermarkets it is approximately $100 \%$. There have been reduced numbers of visitors to the food store, yet grocery expenditure has been risen. During COVID-19 shutdown, consumers saw a decreased supply of several food categories. Interestingly, on the grocery shelves bread and baked items held their position. Consumers rely on long-preservable items, such as dry or canned food, pasta, milk and milk replacements, convenience frozen meals and everyday home cooking. Those food materials were stuck at home due to the shift towards home-baking and faithful myths or misinformation. In fact, the lack of eggs was fascinating not only because of increasing demand but also because of the absence of retail packaging. COVID-19 concerns are wide-ranging, covering both health and financial problems.

In a research conducted in 18 different nations, it has proven that consumers have altered their behaviour as a result of their readiness to eat more healthy food, but to do so at the same time without exceeding the typical budget. Consumers have taken a core approach to return to natural foods and drinks that offer nutrient supplements such as fruits and vegetables, beans, grains or olive oil. At the same time, the influence of COVID-19 on their mental condition worries most customers, which is the reason 
why many customers hunt for dietary products to boost this mood ${ }^{[20]}$. The behaviour of the Italian public on food choices and behaviour was studied by a recent poll of the Italian Agricultural Research and Economic Council (CREA) under COVID-19 quarantine. About 2.900 individuals have answered from all areas of Italy. The findings show healthy eating and drinking: rise for veggies (33 percent), fruit ( 29 percent), vegetables (26.5 percent), and extra-virgin olive oil (21.5 percent). However, 44.5 percent of them were found to have more sweet drinks and 16 percent to drink more wine. The intake of more calories and poor physical exercise revealed a 44 percent weight increase. 37 percent of respondents said their diet should be adapted to reduce weight ${ }^{[21]}$.

Another research indicated that 42 percent of consumers favoured packaging food more than normal among 1000 persons over 18 , while another part of this ratio indicated the pandemic had not changed their position on packaging food. 82 percent of customers believe food they buy is safe to consume during the epidemic. However, a part of the food they buy is unlikely to be safe to buy. A total of 77 percent say food producers can offer sufficient food to suit the requirements of consumers and 16 percent say they cannot afford it ${ }^{[22]}$. Consumers playing a major role in the food supply chain have profoundly influenced the supply chain as changes in consumer behaviour. The outbreak of COVID-19 led to substantial food price increases due to continuous lockdown constraints as well as interruptions of the food supply chains ${ }^{[23]}$. Some customers will focus more on reducing food waste in order to improve food safety ${ }^{[24]}$. However, the contrary is also conceivable since, the shutdown of schools, restaurants or processing facility, most of the perishable food was wasted or dispelled. Moreover, transit challenges during the locking or over-commercial purchase of perishable foods caused a higher levels of food waste ${ }^{[25,26]}$. Changing requests also modify the materials or design of packaging, transportation alternatives and storage conditions ${ }^{[27]}$.

\section{Effects of COVID-19 on Global Food Trade}

Although present conditions appear to be extraordinary, a long way before the COVID-19 crisis has been shown in the sensitivity of food systems to climatic issues and illnesses. Indeed, the food systems were unstable due to multiple occurrences prior to the oil crisis in the 1970 s, the SARS and Ebola epidemic and the food crisis of 200708. Africa Swine Fever sickness crisis just a year ago, a gradual outbreak in East Europe and Asia, has sparked global commodities markets. China, the world's greatest pork producer (with one third of the world's market) and the world's top exporter, lost $37 \%$ of its pigs by $2019^{[28]}$. Ebola has a major detrimental influence on various African countries' agricultural output, marketing and trade industries. Farmers have restricted access to supplies such as seeds, fertilisers, and pesticides on the production side owing to road restrictions, and most regions are facing job shortages (Figure 5) ${ }^{[28]}$. More than $40 \%$ of agricultural land was not farmed for this reason. However, output was not affected by the epidemic since farming regions were

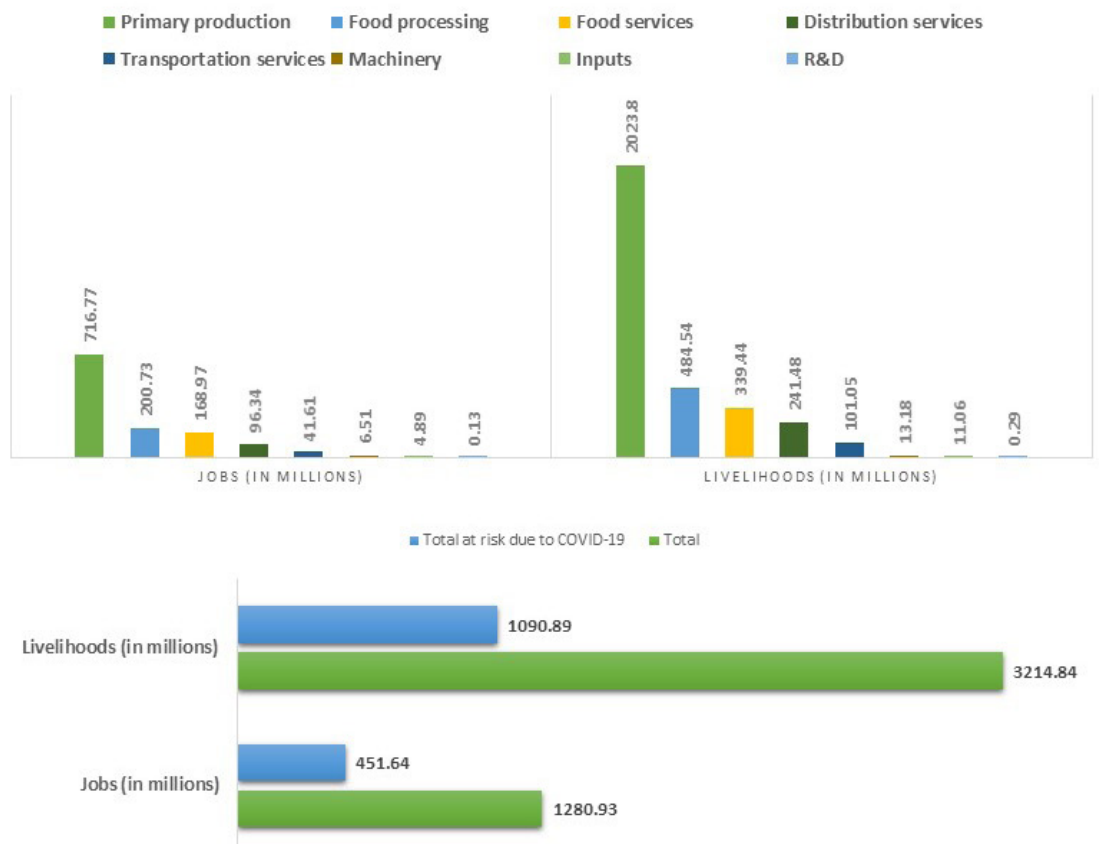

Figure 5. Formal jobs at risk in food systems during this COVID-19 pandemic ${ }^{[28]}$ 
frequently remote from urban populations in geographical areas ${ }^{[29,30]}$.

The current COVID-19 issue has affected several nations' food trade policy to reduce exports and facilitate imports. It is mainly because governments apply export restraints that the quantity of items on the local market is maintained. Although this results in the short-term export limitation, it also has some negative impacts. First, export limitations lead domestic prices to fall, hurting farmers to lose crop output financially and reducing incentives in the business. Secondly, by losing their position in international markets, countries would lose their competitive edge. Thirdly, constraints on exports degrade the reputation of exporters and urge importers to diminish world market confidence, therefore diminishing their faith in international commerce and damaging future business possibilities for exporters ${ }^{[31,32]}$. The COVID-19 pandemic has led to major food trade impacts as a result of the export restrictions, and disruption in the food supply chain. Since export-limited policies have driven up stable food prices such as wheat, maize, and rice and reduced the quality and amount of food eaten ${ }^{[33]}$. The product which is not cultivated or manufactured nationwide could not also be found by customers. Local vendors might not find consumers and result in excess supply and economic losses when export restricting regulations were implemented. Foods that were not cultivated locally but required to be processed, due to constraints and the use of food plants to respond to demand, were also affected badly ${ }^{[34-36]}$.

\section{Business Strategies to Tackle COVID-19 Pandemic}

A crisis committee should be set up to emphasise COVID-19's impact on the food value chain while not waiting too long for some plans and actions to be implemented by the countries. The Committee should be a major player in monitoring progress and proposing measures to lessen the impact of COVID-19 on agricultural production and food supply chain. It is crucial for the committee to work with the business sector to ensure the initiatives are implemented adequately ${ }^{[37]}$. COVID-19, consisting of seven academicians and two members of the Ministry of Agriculture and Forestry, has been set up by the Minister of Agriculture and Forestry in Turkey to take actions and suggestions in respect of agriculture and food under this ongoing pandemic ${ }^{[38]}$. In Turkey, the Ministry of Agriculture and Forestry has informed farmers, production facilities or shops such the slaughterhouses, greenhouses and bakeries about measures and financial aid programmes. Furthermore, the Interior Ministry released lockdown instructions that allow farmers and food manufacturing enterprises to maintain operations at lockdowns ${ }^{[38,39]}$.

Canada has created an Agriculture Response Program that covers $50-75 \%$ of funding that must not be reimbursed as regards health protocols, marketing, transport of products, distribution, strategic initiatives, slaughter efficiency and development ${ }^{[40]}$. In the US, the Department of Agriculture has committed programmes and flexibility to support agricultural farmers associated to the COVID-19 pandemic by providing food aid, supply chain for milk, crop insurance, farmer loans, commodity credit, crop acreage, animal death wages and financial harm ${ }^{[40]}$. In order to reduce the effect of restrictions on migrant labour local residents or jobless might be taught in agricultural operations like planting, weeding or harvesting. In order to make connectivity between locals and farmers, online platforms should be leveraged ${ }^{[41]}$. Unemployed persons or local workers should be encouraged to be agricultural workers by boosting salaries as local employees do not want to work on agriculture since they have a chance to discover better non-agricultural options ${ }^{[42]}$. Outbreak COVID-19 indicated the greatest possible solution to resolve labour shortages over the medium and long term is through working mechanisation policy ${ }^{[41]}$. In order to determine shortages or surpluses that may emerge due to import prohibitions and export limitations, rapid yield forecasting and determination of domestic food supplies must be established. Better food stock management in various locations should be addressed and non-food utilisation of agricultural products (e.g., biofuel) should be minimised ${ }^{[42]}$. Models of crop production information can be employed to help governments decide on food safety or marketing of agricultural products.

In short, as the duration of the COVID-19 is unknown, farmer business models have begun to alter. The development of infrastructure that might be used for the agricultural and food industry should be given considerable attention to companies. Financial incentive packages must also be provided based on the needs of companies ${ }^{[43]}$. Understanding the effects of COVID-19 behind restriction rules is especially significant since the availability levels of food are high and the major production projection is strong. Although these conditions are favourable, governments seek to assure food security because of increased consumer demand and to protect disadvantaged individuals from price rises. However, learning from previous experiences show that avoiding trade restriction regulations can be as beneficial as direct promotion actions to safeguard consumers and agricultural earnings ${ }^{[44,45,46]}$. Therefore, choices and methods for agricultural trade should be altered to reduce the medium-term consequences of the pandemic of COVID-19. 


\section{Conclusions}

During the COVID-19 pandemic a continuous flow of food supply is crucial to prevent the food crisis and minimizing the detrimental impact on the world economy by strengthening agriculture and the food sector, which is one of the most significant sectors combined with health care. Consequently, the seriousness of the crisis must be realised by each nation and, in some cases, it should strengthen or relax the pandemic-dependent measures. The supply network should also be sufficiently flexible to adapt to the food supply chain issues. This is thus determined that the influence of COVID-19 is not excluded from food and agriculture. This pandemic is damaging crops, livestock and fisheries. Today's worldwide scenario needs food safety and security. Concerning the food safety for the most vulnerable sector of the population, the food supply chain has been severely damaged due to COVID-19. Furthermore, most migrant, informal, seasonal farm labour lose their employment that might influence food demand. Therefore, without affecting the food supply chain and taking the food security of the citizens into account, the government of different countries across the globe should use steps to limit the pandemic issue. Each government should establish its own policy to identify the impact and significance of modifying specific trade strategy features on agricultural inputs. This is particularly crucial if domestic agricultural production capacity is restricted and there is an increase in costs for certain foodstuffs.

\section{References}

[1] WHO (2020a), "2019 Novel Coronavirus (2019$\mathrm{nCoV})$ : Strategic preparedness and response plan", World Health Organization, available at: https:// www.who.int/docs/default-source/coronaviruse/srp04022020.pdf?sfvrsn=7ff55ec0_4\&download=true.

[2] Vasavada, P. (2020), "COVID-19 and the food industry: https://www.foodqualityandsafety.com/article/ covid-19-and-the-food-industry-what-we-know.

[3] WHO (2020c), WHO Coronavirus Disease (COVID-19) Dashboard, World Health Organization, available at: https://covid19.who.int/.

[4] Cucinotta, D., \& Vanelli, M. (2020). WHO declares COVID-19 a pandemic. Acta Bio Medica: Atenei Parmensis, 91(1), 157.

[5] Zavatta, G., Perrone, T., \& Figus, C. (2014). Agriculture remains central to the world economy. $60 \%$ of the population depends on agriculture for survival. EXPONet, 27-Oct-2014.

[6] Laborde, D., Martin, W., \& Vos, R. (2020). Poverty and food insecurity could grow dramatically as
COVID-19 spreads. International Food Policy Research Institute (IFPRI), Washington, DC.

[7] WTO. WTO | Frequently asked questions: The WTO and COVID-19. 2020.

[8] Marlow, S. (2020). COVID-19: Effects on the Fertilizer Industry. IHS Market, 24(3), 2-6.

[9] Singh, I. (2020). Agriculture in the time of COVID-19. The Hindu, Business Line.

[10] ILO. ILO Monitor 2nd edition: COVID-19 and the world of work. 2020.

[11] Alonso, E., Gregory, J., Field, F., \& Kirchain, R. (2007). Material availability and the supply chain: risks, effects, and responses.

[12] FAO (20201), "Why export restrictions should not be a response to COVID-19: Learning lessons from experience with rice in Asia and the Pacific", Food and Agriculture Organization, available at: http://www. fao.org/3/ca9362en/CA9362EN.pdf.

[13] FAO. Q and A: COVID-19 pandemic - impact on food and agriculture. 2020.

[14] FAO, IFAD, UNICEF, et al. The State of Food Security and Nutrition in the World 2019, Safeguarding against economic slowdowns and downturns. Rome, FAO. 2019.

[15] FAO. FAO warns of the impact of COVID-19 on school feeding in Latin America and the Caribbean. 2020.

[16] Devereux, S., Béné, C., \& Hoddinott, J. (2020). Conceptualising COVID-19's impacts on household food security. Food Security, 12(4), 769-772.

[17] Flynn, D. (2020). CDC provides first guidance to a specific meat plant for combating COVID-19 among employees.

[18] Reardon, T., Bellemare, M. F., \& Zilberman, D. (2020). How COVID-19 may disrupt food supply chains in developing countries. IFPRI book chapters, 78-80.

[19] Muscogiuri, G., Barrea, L., Savastano, S., \& Colao, A. (2020). Nutritional recommendations for CoVID-19 quarantine. European Journal of Clinical Nutrition, 74(6), 850-851.

[20] Hughes, M. (2020). Evolving eating habits as a result of COVID-19. New Food.

[21] CREA (2020), "How did italian eating habits change during lockdown?", The Council for Agricultural Research and Economics, available at: https://www. foodnavigator.com/Article/2020/06/05/Coronavirus-lockdown-found-to-worsen-childhood-obesity.

[22] IFIC (2020), "COVID-19 Impact on food purchasing, eating behaviors, and perceptions of food safety", International Food Information Council, available at: 
https://foodinsight.org/consumer-survey-covid-19simpact-on-food-purchasing/.

[23] EDP (2020), "Shedding Light on Changing Consumer Behaviour with Economic Data", European Data Portal, available at: https://www.europeandataportal. eu/en/covid-19/stories/shedding-light-changing-consumer-behaviour-economic-data.

[24] Shafiee-Jood, M., \& Cai, X. (2016). Reducing food loss and waste to enhance food security and environmental sustainability. Environmental science \& technology, 50(16), 8432-8443.

[25] Sharma, H. B., Vanapalli, K. R., Cheela, V. S., Ranjan, V. P., Jaglan, A. K., Dubey, B., ... \& Bhattacharya, J. (2020). Challenges, opportunities, and innovations for effective solid waste management during and post COVID-19 pandemic. Resources, conservation and recycling, 162, 105052.

[26] Fleetwood, J. (2020). Social justice, food loss, and the sustainable development goals in the era of COVID-19. Sustainability, 12(12), 5027.

[27] Reynold, M. (2020), "Supply Chains Race to Match Shifting COVID-19 Consumer Behavior, Packaging World", available at: https://www.packworld.com/ covid-19/article/21132561/supply-chains-race-tomatch-shifting-covid19-consumer-behavior.

[28] IPES (2020), "COVID-19 and the crisis in food systems: Symptoms, causes, and potential solutions", The International Panel of Experts on Sustainable Food System, available at: http://www.ipes-food. org/_img/upload/files/COVID-19_CommuniqueEN. pdf.

[29] Torero, M. (2020). Prepare food systems for a longhaul fight against COVID-19. IFPRI book chapters, 118-121.

[30] Shahidi, F. (2020). Does COVID-19 affect food safety and security? Journal of Food Bioactives, 9.

[31] Espitia, A., Rocha, N., \& Ruta, M. (2020). Covid-19 and food protectionism: the impact of the pandemic and export restrictions on world food markets. The World Bank.

[32] FAO (2020a), "Adjusting business models to sustain agri-food enterprises during COVID-19", Food and Agriculture Organization, available at: http://www. fao.org/3/ca8996en/CA8996EN.pdf.

[33] Fyles, H., \& Madramootoo, C. (2016). Key drivers of food insecurity. In Emerging Technologies for Promoting Food Security (pp. 1-19). Woodhead Publishing.

[34] Arianina, K., \& Morris, P. (2020), "COVID-19 Export Restrictions Threaten Global Food Supply", available at: https://www.squirepattonboggs.com/-/ media/files/insights/publications/2020/05/covid-19export-restrictions-threaten-global-food.

[35] Reddy, V. R., Singh, S. K., \& Anbumozhi, V. (2016). Food supply chain disruption due to natural disasters: Entities, risks, and strategies for resilience. ERIA Discussion Paper, 18.

[36] Ndemezo, E., Ndikubwimana, J. B., \& Dukunde, A. (2018). Determinants of capacity utilization of food and beverage manufacturing firms in rwanda: do tax incentives matter? Available at SSRN 3217757.

[37] Sahoo, J. P., Nath, S., Ghosh, L., \& Samal, K. C. (2021). Concepts of Immunity and Recent Immunization Programme against COVID-19 in India. Biotica Research Today, 3(2), 103-106.

[38] MAF (2020), 'COVID-19 Precautions", Republic of Turkey Ministry of Agricultural and Forestry, available at: https://www.tarimorman.gov.tr.

[39] MIA (2020), "COVID-19 Precautions", Republic of Turkey Ministry of Internal Affairs, available at: https://www.icisleri.gov.tr/.

[40] Novascatia (2020), 'COVID-19: Agriculture Response Program", available at: https:/novascotia.ca/ coronavirus/agriculture-response-program/.

[41] Troskie, D. P. (2020), "Impact of Covid-19 On Agriculture And Food In The Western Cape", Western Cape Department of Agriculture, availbale at: https://www.hortgro.co.za/wp-content/uploads/ docs/2020/03/agricultural-scenariosc.pdf.

[42] Martin, P. L. (2016), "Migrant Workers in Commercial Agriculture", International Labour Office, accessed at: http://www.oit.org/wcmsp5/groups/public/---ed_protect/---protrav/---migrant/documents/ publication/wcms_538710.pdf.

[43] USDA (2020), 'Coronavirus and USDA Assistance for Farmers", U.S. Department of Agriculture, available at: https://www.farmers.gov/coronavirus.

[44] Sahoo, J. P., Mohapatra, U., Mahapatra, S. S., Panda, K. K., Ganesh, P., Mishra, A. P., \& Behera, S. K. (2020). An immunological outlook on sars coronavirus (SARS-CoV-2) and Its current clinical status. Journal of Pharmaceutical Research International, 37-59.

[45] Behera, L., Sahoo, J. P., Mahapatra, S. S., Praveena, J., Dash, T., \& Samal, K. C. (2020). Insights into the SARS-CoV-2 Diagnosis in India: Present Status and Future Prospects. Journal of Pharmaceutical Research International, 38-53.

[46] Martin, W.J., Glauber, J. W, (2020), “Trade policy and food security", In COVID-19 and Trade Policy. 